\title{
Exploring the epidemiological changes of common respiratory viruses since the COVID-19 pandemic: a hospital study in Hangzhou, China
}

\author{
Xinke $\mathrm{Du}^{1}$ - Guangsheng $\mathrm{Wu}^{1}{ }^{1}$ - Yafei Zhu ${ }^{1}$ - Siqi Zhang ${ }^{2}$ \\ Received: 5 May 2021 / Accepted: 9 July 2021 / Published online: 4 September 2021 \\ (c) The Author(s), under exclusive licence to Springer-Verlag GmbH Austria, part of Springer Nature 2021
}

\begin{abstract}
Adenovirus, respiratory syncytial virus, and influenza virus are common causes of respiratory infections. The COVID-19 pandemic had a significant impact on their prevalence. The aim of this study was to analyze the epidemic changes of common respiratory viruses in the Affiliated Hospital of Hangzhou Normal University in Hangzhou, China, from October of 2017 to February of 2021. We collected statistics from 121,529 patients in the outpatient and inpatient departments of the hospital who had throat or nose swabs collected for testing for four virus antigens by the colloidal gold method. Of these, 13,200 (10.86\%) were positive for influenza A virus, 8,402 (6.91\%) were positive for influenza B virus, 6,056 (4.98\%) were positive for adenovirus, and $4,739(3.90 \%)$ were positive for respiratory syncytial virus. The positivity rates of the influenza A virus ( $0-14$ years old, $P=0.376$; over 14 years old, $P=0.197)$ and respiratory syncytial virus $(0-14$ years old, $P=0.763$; over 14 years old, $P=0.465$ ) did not differ significantly by gender. After January of 2020, influenza virus infection decreased significantly. The positivity rate of respiratory syncytial virus remained high, and its epidemic season was similar to before. Strict respiratory protection and regulation of crowd activities have a great impact on the epidemic characteristics of viruses. After major changes in the public health environment, virus epidemics and their mutations should be monitored closely, extensively, and continuously.
\end{abstract}

\section{Introduction}

Adenovirus (ADV), respiratory syncytial virus (RSV), influenza A virus (IFVA), and influenza B virus (IFVB) are important causes of respiratory infections. These viruses cause fever, cough, and headache as well as impaired liver, kidney, and heart function, and severe infections can lead to pneumonia, sepsis, and even death. They also can be associated with asthma [1,2]. IFVA and IFVB epidemics cause a large number of deaths and major economic losses each year [3]. ADV causes respiratory tract infections, cystitis, hepatitis, and digestive tract infections [4]. RSV is the most common pathogen causing respiratory infection in infants

Handling Editor: William G Dundon.

Guangsheng Wu

wuguangsheng1983@126.com

1 Department of Pediatrics, The Affiliated Hospital of Hangzhou Normal University, No. 126 Wenzhou Road, Gongchenqiao Street, Gongshu District, Hangzhou, China

2 Clinical Medicine College of Hangzhou Normal University, Hangzhou, China and is also one of the most important pathogens causing respiratory infections in adults $[5,6]$.

The COVID-19 epidemic has had an enormous impact on health internationally since 2019 . The prevalence of common respiratory viruses may have changed since this pandemic began. In this study, we investigated the prevalence of common respiratory viruses in Hangzhou, China, since October of 2017 and determined the positivity rate of these viruses in different age groups and seasons. This will provide a scientific basis for the subsequent diagnosis, treatment, and prevention of infections with these viruses.

\section{Methods}

This is a retrospective analysis of clinical statistics about patients who visited the outpatient and inpatient departments of the Affiliated Hospital of Hangzhou Normal University from October 1, 2017, to February 28, 2021. Not all of these patients had respiratory symptoms. Throat or nose swabs were collected, and one sample was analysed simultaneously for four virus antigens, including IFVA, IFVB, $\mathrm{RSV}$, and ADV. Samples that lacked all required information 
were excluded. The data include basic information, such as demographics, period of biological sample collection, testing results, and dates. The subjects were divided into six age groups: 0-2 years old, 3-6 years old, 7-14 years old, 15-34 years old, 35-59 years old, and over 59 years old. Written informed consent was waived due to the retrospective nature of the study. The study plan was approved by the Scientific Ethics Committee of the Clinical Medical College of Hangzhou Normal University.

The IFVA and IFVB antigens were detected using an Influenza A \& Influenza B Nucleoprotein Antigen Test Kit (colloidal gold method, KaiBiLi), ADV antigen was detected using an Adenovirus Antigen Test Kit (colloidal gold method, KaiBiL), and RSV antigen was detected using a Respiratory Syncytial Virus Antigen Test Kit (colloidal gold method, KaiBiL). The test kits were produced by Hangzhou Genesis Biodetection \& Biocontrol Ltd, China (http:// www.hgb.com.cn/En/about.html). Samples obtained from the throat or nose swabs were immediately prepared for analysis. Samples were stored at $2{ }^{\circ} \mathrm{C}$ to $8{ }^{\circ} \mathrm{C}$ for up to eight hours if they were not analyzed immediately.

We analyzed the monthly sample number, age, gender, and testing date. The data were reported as the number of cases and the positivity rate (\%). We used the chi-square test and Fisher's exact test to conduct statistical analysis using SPSS 23.0 statistical software. $P<0.05$ was considered statistically significant, and the calibrated test level for pairwise comparison between groups was $P^{\prime}=0.05 /[\mathrm{K}$
$(\mathrm{K}-1) / 2]$, where $\mathrm{K}$ represents the number of independent samples for pairwise comparison between multiple groups.

\section{Results}

We collected information on a total of 121,529 patients, ranging in age from $20 \mathrm{~h}$ to 102 years old. Of these, 81,406 patients were $0-14$ years old, and 40,123 were over 14 years old. In all, 31,253 patients were positive for only one virus, 1,811 were positive for two viruses, 388 were positive for three viruses, 25 were positive for four viruses, and 88,052 were negative for all of the viruses tested. Among all samples, 13,200 (10.86\%) were positive for IFVA, 8,402 (6.91\%) were positive for IFVB, 6,056 (4.98\%) were positive for ADV, and 4,739 (3.90\%) were positive for RSV. The mixed infection rate (coinfection with more than one virus) was the highest for ADV, and the highest coinfection rates were observed with ADV+FLU and ADV+RSV mixed infection (Fig. 1), which is consistent with a previous study [7]. The positivity rate of each virus in patients under 15 years of age was higher than those in patients over 14 years of age (Fig. 1, Table 1). The positivity rate of mixed infection in the 0 to 14-year-old age group was higher than in those over 14 years old (Fig. 1).

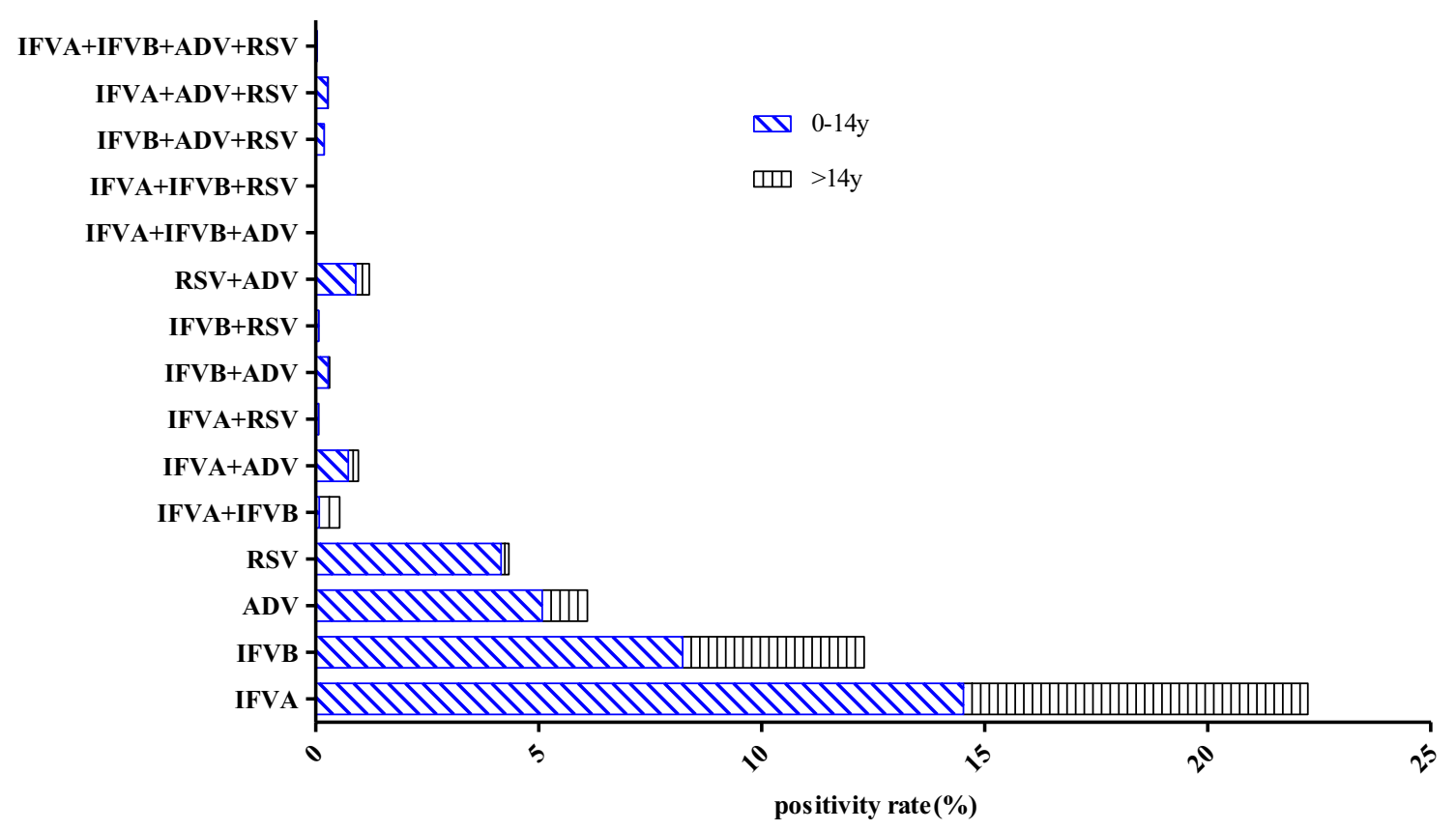

Fig. 1 Virus positivity rates in the group aged 0-14 years old and in the group aged above 14 years old. IFVA, influenza A virus; IFVB, influenza B virus; ADV, adenovirus; RSV, respiratory syncytial virus 
Table 1 Comparison of virus positivity rates between males and females (positive cases/ number of samples [\%])

\begin{tabular}{llllrl}
\hline & & Male & Female & $\chi^{2}$ & $P$-value \\
\hline IFVA & $0-14 \mathrm{y}$ & $6823 / 43736(15.60)$ & $5962 / 37670(15.83)$ & 0.784 & 0.376 \\
& $>14 \mathrm{y}$ & $1379 / 17221(8.01)$ & $1754 / 22902(7.66)$ & 1.663 & 0.197 \\
\multirow{2}{*}{ FFVB } & $0-14 \mathrm{y}$ & $3930 / 43736(8.99)$ & $3301 / 37670(8.76)$ & 1.241 & 0.265 \\
& $>14 \mathrm{y}$ & $728 / 17221(4.23)$ & $935 / 22902(4.08)$ & 0.519 & 0.471 \\
\multirow{2}{*}{ ADV } & $0-14 \mathrm{y}$ & $3622 / 43736(8.28)$ & $2481 / 37670(6.59)$ & 83.881 & 0.000 \\
& $>14 \mathrm{y}$ & $215 / 17221(1.25)$ & $251 / 22902(1.10)$ & 1.991 & 0.158 \\
\multirow{2}{*}{ RSV } & $0-14 \mathrm{y}$ & $2583 / 43736(5.91)$ & $2206 / 37670(5.86)$ & 0.091 & 0.763 \\
& $>14 \mathrm{y}$ & $51 / 17221(0.30)$ & $59 / 22902(0.26)$ & 0.534 & 0.465 \\
\hline
\end{tabular}

IFVA, influenza A virus; IFVB, influenza B virus; RSV, respiratory syncytial virus; ADV, adenovirus

\section{Differences in age}

Pairwise comparison of the virus positivity rate in different age groups (Table 2) showed that the majority of IFVA-infected patients were 3-6 years old or 7-14 years old, and there was no statistical difference between these two groups. The IFVA positivity rate of the 0 - to 2-yearold group ranked second, and the IFVA positivity rate in those above 14 years old was lower than that in those below 14 years old. IFVB infection was most common in the 7- to 14-year-old group, followed by the 3- to 6-yearold group, and a pairwise comparison between the two groups showed statistical differences. The positivity rate of ADV in those aged 3-6 years old was highest, while the 7to 14-year-old group ranked second, and the 0- to 2-yearold group ranked third (Table 2). There was no significant difference in the ADV positivity rate between those aged 35-59 years old and those over 60 years old, which had the lowest rates. The positivity rate of RSV in the 0- to 2-year-old group was significantly higher than that in other age groups. The positivity rate of RSV in the 3- to 6 -year-old group was the second highest. There was no significant difference in RSV infection rates among those aged 15-34 years old, 35-59 years old, and over 59 years old. For the same age group, the positivity rates of IFVA and RSV in the 0- to 2-year-old group were higher than those for IFVB and ADV. In the 3- to 6-year-old group, the most common virus was IFVA, followed by ADV and IFVB, and the RSV positivity rate was relatively low. In the 7- to 14-year-old group, IFVA and IFVB were the most common viruses, ADV ranked second, and RSV infection was rare. For people over 14 years of age, IFVA and IFVB were the most common infections, and the ADV and RSV infection rates were very low (Table 1).

\section{Difference in seasonality}

We analyzed the monthly positivity rates of IFVA, IFVB, ADV, and RSV from October 1, 2017, to February 28, 2021. On the abaxial axis, $x=-2$ refers to October of 2017, $x=-1$ refers to November of 2017, $x=0$ refers to December of 2017, and $x=1$ refers to January of 2018. We plotted the fluctuation curve of the monthly positivity rate (Fig. 2). In 2018 and 2019, peaks of IFVA infections appeared in February. In 2020, the peak of IFVA infection appeared in December. There was no significant peak of IFVA infection from December of 2020 to February of 2021 (Fig. 2). The positivity rate of IFVA in the 0 - to 14 -year-old group
Table 2 Results for each virus by age group (positive cases [rate\%])

\begin{tabular}{llllll}
\hline & Cases*1 $^{*}$ & IFVA $(\%) *^{2}$ & IFVB $(\%)$ & ADV $(\%)$ & RSV (\%) \\
\hline $0-2$ y & 23,264 & $2811(12.08)$ & $1089(4.68)$ & $1112(4.78)$ & $2618(11.25)$ \\
$3-6$ y & 30,810 & $5200(16.88)$ & $2861(9.29)$ & $3227(10.47)$ & $1582(5.13)$ \\
$7-14$ y & 27,332 & $4784(17.50)$ & $3270(11.96)$ & $1762(6.45)$ & $430(1.57)$ \\
$15-34$ y & 21,401 & $1646(7.69)$ & $1136(5.31)$ & $349(1.63)$ & $62(0.29)$ \\
$35-59$ y & 12,509 & $997(7.97)$ & $418(3.34)$ & $92(0.74)$ & $23(0.18)$ \\
$>59$ y & 6213 & $400(6.44)$ & $119(1.92)$ & $25(0.40)$ & $25(0.40)$ \\
$\chi^{2}$ &.. & 1962.348 & 1970.835 & 3058.611 & 5284.138 \\
$P$-value &.. & 0.000 & 0.000 & 0.000 & 0.000 \\
\hline
\end{tabular}

IFVA, influenza A virus; IFVB, influenza B virus; RSV, respiratory syncytial virus; ADV, adenovirus; *1, Cases detected in each age group; $*^{2}$, number of positive cases and the positivity rate of the corresponding virus in each age group 
Fig. 2 Monthly positivity rate curves of four viruses from October 2017 to February 2021. IFVA, influenza A virus; IFVB, influenza $B$ virus, RSV, respiratory syncytial virus; ADV, adenovirus
Monthly positivity rate curves of four virus from October 2017 to February 2021

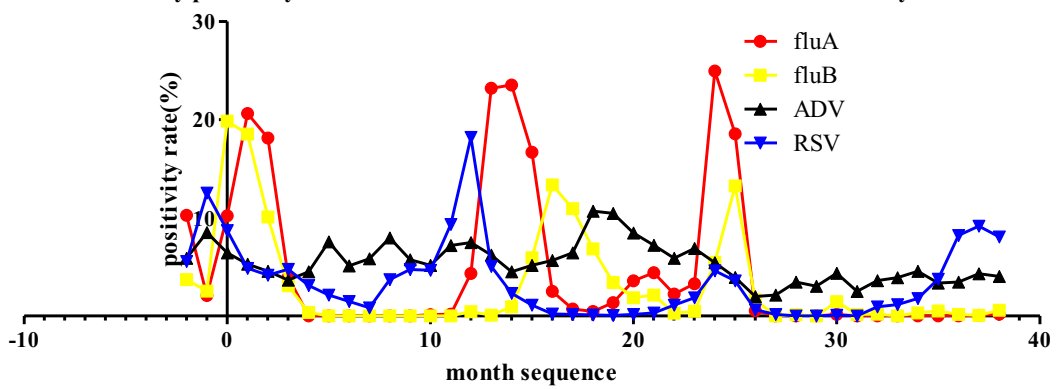

IFVA monthly positivity rate curves of different age groups from October 2017 to February 2021

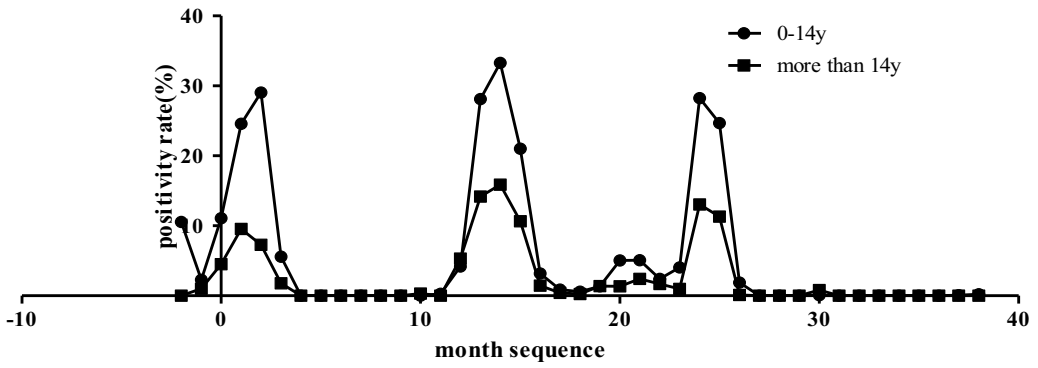

IFVB monthly positivity rate curves of different age groups from October 2017 to February 2021

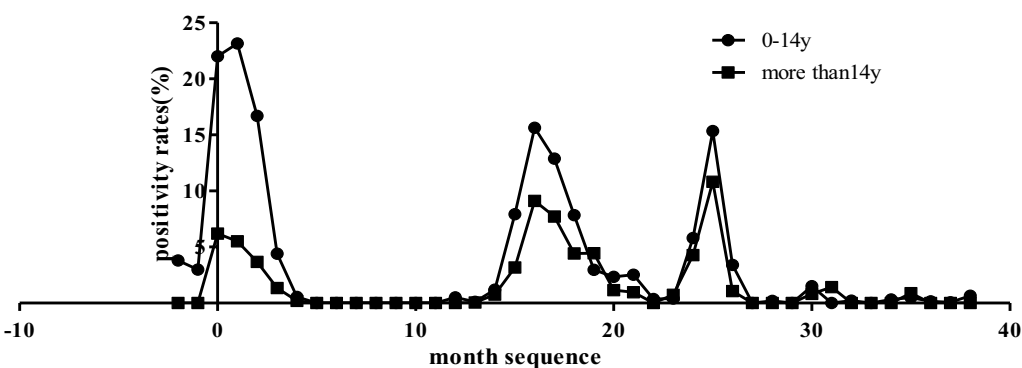

ADV monthly positivity rate curves of different age groups from October 2017 to February 2021

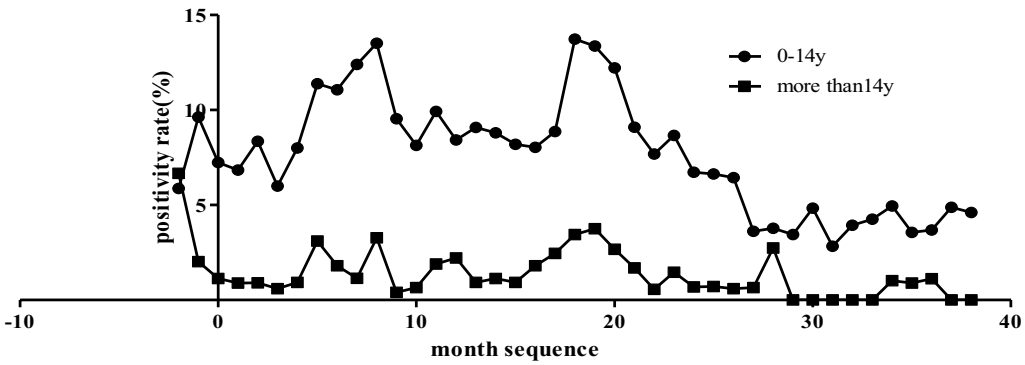

RSV monthly positivity rate curves of different age groups from October 2017 to

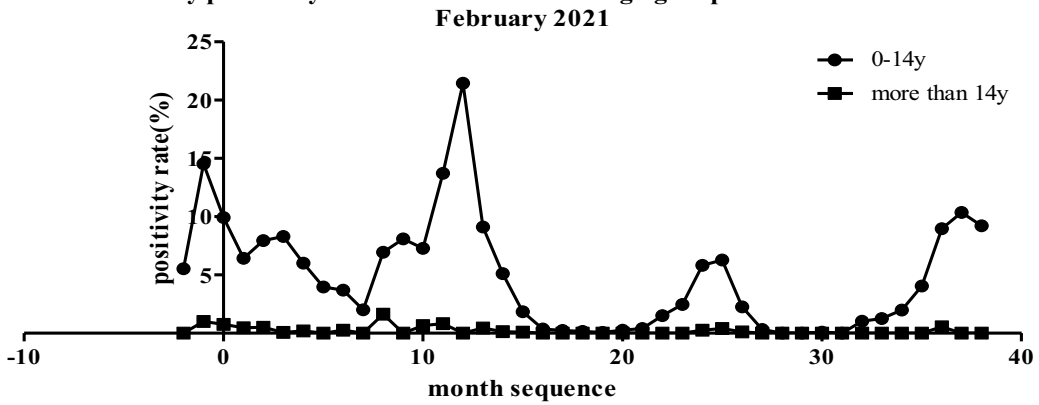


was higher than that in those over 14 years of age in four periods: 2017.12.01-2018.02.28, 2018.12.01-2019.02.28, 2019.12.01-2020.02.29, and 2020.12.01-2021.02.28. The positivity rate of IFVA between December of 2020 and February of 2021 decreased significantly compared with the same period in previous years, regardless of age (Table 3). Peaks of IFVB infection appeared in December of 2017, January of 2018, and January of 2020, but in 2019, it appeared in April. There was no peak of IFVB infection from December of 2020 to February of 2021 (Fig. 2). In the 0 - to 14-year-old group, there was no statistically significant difference in the ADV positivity rates between June-August 2018 and June-August 2019. The ADV positivity rates in these two periods were higher than that in 2020 (Fig. 2, Table 4).
The positivity rate of ADV after January of 2020 was lower than in the previous two years. The peak of RSV infection in the 0- to 14-year-old group in 2017 was in November. In 2018 and 2019, the RSV infection peak occurred in December. A significant RSV peak occurred between December of 2020 and January of 2021, which was roughly the same peak time as in the previous three years (Fig. 2). We made a pairwise comparison of the RSV positivity rate between four periods: 2017.10.012018.02.28, 2018.10.01-2019.02.28, 2019.10.012020.02.29, and 2020.10.01-2021.02.28 (Table 5). For people over 14 years old, there was no significant difference in the positivity rate among the four periods. For those younger than 14 years old, the RSV positivity rate was the highest in 2018.10.01-2019.02.28 and the lowest in 2019.10.01-2020.02.29. However, there was no statistical difference in the positivity rate between the other two periods of 2017.10.01-2018.02.28 and 2020.10.01-2021.02.28.
Table 3 Comparison of influenza A virus positivity different years (positive cases/ number of samples [\%]) during December-February in
Table 4 Comparison of adenovirus positivity during June to August in different years (positive cases/number of samples [\%])

\begin{tabular}{llllll}
\hline & All & $0-14 \mathrm{y}$ & $>14 \mathrm{y}$ & \multicolumn{2}{l}{$\begin{array}{l}\text { Comparison of two } \\
\text { age groups }\end{array}$} \\
\cline { 3 - 6 } & & & & $\chi^{2}$ & $P$-value \\
\hline 2017 & $4830 / 26,255(18.40)$ & $4161 / 18,258(22.79)$ & $659 / 7997(8.24)$ & 785.440 & 0.00 \\
2018 & $3728 / 18,542(20.11)$ & $2743 / 11,474(23.91)$ & $1015 / 7068(14.36)$ & 246.625 & 0.00 \\
2019 & $5453 / 26,304(20.73)$ & $4433 / 16,849(26.31)$ & $1020 / 9455(10.79)$ & 887.980 & 0.00 \\
2020 & $2 / 4231(0.05)$ & $2 / 3790(0.05)$ & $0 / 441(0.00)$ &.. & 1.000 \\
$\chi^{2}$ & 1069.163 & 1248.899 & 200.899 &.. &.. \\
$P$-value & 0.000 & 0.000 & 0.000 &.. &.. \\
\hline
\end{tabular}

\begin{tabular}{llllll}
\hline & All & $0-14 \mathrm{y}$ & $>14 \mathrm{y}$ & \multicolumn{2}{l}{$\begin{array}{l}\text { Comparison of two } \\
\text { age groups }\end{array}$} \\
\cline { 5 - 6 } & & & & $\chi^{2}$ & $P$-value \\
\hline 2018 & $111 / 1770(6.27)$ & $90 / 726(12.40)$ & $21 / 1044(2.01)$ & 78.573 & 0.000 \\
2019 & $609 / 6019(10.12)$ & $545 / 4095(13.31)$ & $64 / 1924(3.33)$ & 143.433 & 0.000 \\
2020 & $89 / 2401(3.71)$ & $89 / 2165(4.11)$ & $0 / 236(0.00)$ & 10.075 & 0.002 \\
$\chi^{2}$ & 104.677 & 132.589 & 11.474 &.. &.. \\
$P$-value & 0.00 & 0.000 & 0.003 &.. &.. \\
\hline
\end{tabular}

Table 5 Comparison of respiratory syncytial virus positivity during OctoberFebruary in different years (positive cases/number of samples [\%])

\begin{tabular}{|c|c|c|c|c|c|}
\hline & \multirow[t]{2}{*}{ All } & \multirow[t]{2}{*}{$0-14$ y } & \multirow[t]{2}{*}{$>14 \mathrm{y}$} & \multicolumn{2}{|c|}{$\begin{array}{l}\text { Comparison of two } \\
\text { age groups }\end{array}$} \\
\hline & & & & $\chi^{2}$ & $P$-value \\
\hline 2017 & $1503 / 27,519(5.46)$ & $1461 / 19,408(7.53)$ & $41 / 8111(0.51)$ & 546.668 & 0.000 \\
\hline 2018 & $1319 / 20,399(6.47)$ & $1394 / 12,656(11.01)$ & $25 / 7743(0.32)$ & 848.451 & 0.000 \\
\hline 2019 & $1083 / 29,403(3.68)$ & $1051 / 19,176(5.48)$ & $32 / 10,227(0.31)$ & 502.119 & 0.000 \\
\hline 2020 & $439 / 6783(6.47)$ & $438 / 6132(7.14)$ & $1 / 651(0.15)$ & 47.580 & 0.000 \\
\hline$\chi^{2}$ & 230.879 & 335.812 & 5.430 &.. & .. \\
\hline$P$-value & 0.000 & 0.000 & 0.128 & .. & .. \\
\hline
\end{tabular}




\section{Differences in gender}

The positivity rate of IFVA in males was higher than that in females. However, after further differentiation by age, there was no significant difference in the IFVA infection rates between women and men. The IFVB and RSV positivity rates of males and females were similar to those for IFVA. The positivity rate of ADV in males aged 0-14 was higher than that in females. However, the group over 14 years of age demonstrated no significant difference in ADV positivity between men and women (Table 1).

\section{Discussion}

Influenza virus, ADV, and RSV are common pathogens causing human respiratory tract infections. Previous studies have shown that the populations most susceptible to influenza virus are young children, the elderly, immunodeficient patients, and women who are more than three months pregnant [8-10]. Our study showed that the age group most susceptible to influenza virus infection was the 3- to 14-year-old group. This may be due to the daily activities these children partake in and the fact that their activity space is relatively concentrated, which increases the risk of close exposure to aerosols containing viruses or respiratory pathogens.

No significant difference in influenza virus positivity rate was found between males and females, which is inconsistent with previous studies showing that women were more likely to test positive for influenza virus [11]. Studies performed in some countries have indicated that men were at higher risk of influenza virus infection than women, but there are no such obvious differences in countries with large populations, such as the United States or China [12]. Age, racial differences, and regional medical care conditions may be responsible for these inconsistent results. According to our research, the IFVA prevalence season was winter, and the IFVB prevalence season was winter or spring, which was similar to previous research findings [11, 13]. Previous studies have shown that influenza epidemics occur yearly during the winter and spring, which is consistent with the results of this study. This is partly because cold and dry conditions facilitate virus transmission [14]. Since February 2019, no seasonal influenza epidemic peak has been observed. However, influenza virus A can spread between animals and humans and is prone to mutate to produce a variety of new subtypes. A future mutation or subtype may trigger another influenza pandemic.

Previous studies have suggested that there are certain age and seasonal differences in the prevalence of ADV.
Zheng et al. found that the ADV infection rate in adults was higher than that in children [15], but Wu et al. found that the majority of children with adenovirus respiratory tract infections were under 6 years of age [16]. Our study showed that ADV infection was most common in children aged 3-6 years, that the infection rate in those aged 7-14 years ranked second, that the infection rate in the group aged 0-2 years ranked third, and that the positivity rate of ADV in patients over age 14 year was low. This is similar to the findings of $\mathrm{Wu}$ et al. We speculate that the high positive rate of ADV in children 3-6 years of age was because they were in kindergarten in Hangzhou and prone to cross-infection. According to another study on ADV prevalence in adults in Harbin, China, ADV incidence typically was highest in the spring, followed by winter [17]. A study conducted in Mainz, Germany [18], showed a negative correlation between ADV infection and temperature, which was similar to the results reported in Harbin. However, our study showed a higher incidence of ADV in July-August. Another 19-year epidemiological study on ADV infection in children hospitalized in Autonomous City, Buenos Aires [19], found that a peak in ADV infection in children occurred in July, which was similar to our results. Interestingly, the climate in Autonomous City, Buenos Aires, is similar to that in the region of our study, which is relatively warm and humid. The seasonal characteristics of ADV incidence varied among studies due to differences in regional climate, sample size, study time-span, and other factors. Long-term monitoring and analysis of the ADV positivity rate in different regions must be carried out, and the correlation between ADV positivity rate and climate factors requires further study.

Previous studies showed that the RSV infection rate rose in late autumn and early winter [6,20]. Similarly, our work showed that the peak RSV pandemic season was from November to January. Previous studies comparing RSV infection rates between men and women have shown different results. Some studies suggest no gender difference in RSV infection rates [11,21], while others suggest that RSV infection rates are higher in males than in females [19, 22]. Our study showed no significant gender difference in the RSV positivity rate, regardless of age. Therefore, both men and women are susceptible to RSV infection. Rice et al. determined that the seasonal epidemic of RSV was on average 6 weeks earlier than the IFVA epidemic, although in some years the RSV and IFVA epidemics occurred simultaneously [11]. Our study showed similar results. From late 2017 to early 2018 and late 2018 to early 2019 , the RSV prevalence season was about 8-12 weeks earlier than that of IFVA, but from late 2019 to early 2020, the RSV prevalence season was almost at the same time as that of IFVA. An influenza outbreak may be imminent about two months after an RSV epidemic. 
The coronavirus pandemic has had varied effects on the prevalence of the three respiratory viruses. After the COVID-19 outbreak, awareness of health and respiratory protection improved. The government actively promoted hand sanitization, wearing surgical masks, social distancing, school holidays, factory shutdowns, home isolation, and reduced social activities. We conclude that these measures decreased ADV and influenza virus infections after February 2019 [23-27]. Reduced industrial production and improved environmental quality also play important roles in decreasing the rate of respiratory virus infections $[28,29]$. However, compared with previous years, the RSV positivity rate from December of 2020 to February of 2021 was still quite high, possibly due to the susceptibility of those under 2 years old to RSV infection. The respiratory tracts of these children are not protected sufficiently by masks, and they have weak immune systems. Furthermore, an effective RSV vaccine has not yet been developed.

The detection method used in this study did not allow classification of virus subtypes. Further virus classification and epidemiological surveillance of the circulating subtype will reveal more-detailed epidemiological characteristics [30]. Our study data were collected from one hospital, and the patient sourcing had strong regional limitations. The results of a multi-center research trial may provide further information for control, prevention, and treatment of respiratory virus infections.

In conclusion, the influenza epidemic season is typically in the winter but occasionally in the spring. ADV is prevalent throughout the year and may have a small epidemic peak in the summer. The RSV epidemic season is in late autumn and early winter. After the COVID-19 epidemic, an influenza peak was not observed, and the ADV infection rate decreased. However, the RSV epidemic season and infection rate were not significantly affected. This phenomenon must be studied further. Respiratory virus infections may be reduced by the use of masks, vaccination efforts, social distancing measures, and enhanced air quality control. After these dramatic public health changes, the characteristics of viral epidemics and their mutations should be extensively and continuously monitored and analyzed.

Acknowledgements We wish to thank the clinical lab and information department for their help in testing and data collection. We sincerely acknowledge the help of numerous people who are not listed as authors. The views expressed in this publication are solely those of the author.

Author contributions Xinke Du collated information, conducted the statistical analysis, and wrote the manuscript draft. Guangsheng Wu and Yafei Zhu contributed to the literature search and data collection. Siqi Zhang helped with data disposal. All authors contributed to study conception and design and manuscript review and have verified the underlying data.
Funding source We received no funding, grants, or other means of financial support for this study.

Data availability statement The data that support these study findings are available from the corresponding author upon reasonable request. The data are not publicly available due to privacy or ethical restrictions.

\section{Declarations}

Competing interests The authors declare they have no conflicts of interest concerning this research study and paper.

\section{References}

1. Papadopoulos NG, Christodoulou I, Rohde G et al (2011) Viruses and bacteria in acute asthma exacerbations-a GA2LEN-DARE systematic review. Allergy 66:458-468. https://doi.org/10.1111/j. 1398-9995.2010.02505.x

2. Sigurs N, Aljassim F, Kjellman B, Robinson PD, Sigurbergsson F, Bjarnason R (2010) Asthma and allergy patterns over 18 years after severe RSV bronchiolitis in the first year of life. Thorax 65:1045-1052. https://doi.org/10.1136/thx.2009.121582

3. Krammer F, Smith GJD, Fouchier RAM et al (2018) Influenza. Nat Rev Dis Primers 4(1):3. https://doi.org/10.1038/ s41572-018-0002-y

4. Lynch JP, Kajon AE (2016) Adenovirus: epidemiology, global spread of novel serotypes, and advances in treatment and prevention. Semin Respir Crit Care Med 37(4):586-602. https://doi.org/ 10.1055/s-0036-1584923

5. Shi T, McAllister DA, O'Brien KL et al (2017) Global, regional, and national disease burden estimates of acute lower respiratory infections due to respiratory syncytial virus in young children in 2015: a systematic review and modelling study. Lancet 390(10098):946-958. https://doi.org/10.1016/S0140-6736(17) 30938-8

6. Coultas JA, Smyth R, Openshaw PJ (2019) Respiratory syncytial virus (RSV): a scourge from infancy to old age. Thorax 74(10):986-993. https://doi.org/10.1136/thoraxjnl-2018-212212

7. Mandelia Y, Procop GW, Richter SS, Worley S, Liu W, Esper F (2020) Dynamics and predisposition of respiratory viral coinfections in children and adults. Clin Microbiol Infect. https:// doi.org/10.1016/j.cmi.2020.05.042

8. Thompson WW et al (2004) Influenza-associated hospitalizations in the United States. JAMA 292:1333-1340. https://doi.org/10. 1001/jama.292.11.1333

9. Walsh EE, Cox C, Falsey AR (2002) Clinical features of influenza A virus infection in older hospitalized persons. J Am Geriatr Soc 50:1498-1503. https://doi.org/10.1046/j.1532-5415.2002.50404.x

10. Neuzil KM, Reed GW, Mitchel EF, Simonsen L, Griffin MR (1998) Impact of influenza on acute cardiopulmonary hospitalizations in pregnant women. Am J Epidemiol 148:1094-1102. https://doi.org/10.1093/oxfordjournals.aje.a009587

11. Price OH, Sullivan SG, Sutterby C, Druce J, Carville KS (2019) Using routine testing data to understand circulation patterns of influenza A, respiratory syncytial virus and other respiratory viruses in Victoria, Australia. Epidemiol Infect 147:e221. https:// doi.org/10.1017/S0950268819001055

12. Gabriel G, Arck PC (2014) Sex, immunity and influenza. J Infect Dis 209(Suppl 3):S93-S99. https://doi.org/10.1093/infdis/jiu020

13. Peteranderl C, Schmoldt C, Herold S (2016) Human influenza virus infections. Semin Respir Crit Care Med 37(4):487-500. https://doi.org/10.1055/s-0036-1584801 
14. Lowen AC, Mubareka S, Steel J, Palese P (2007) Influenza virus transmission is dependent on relative humidity and temperature. PLoS Pathog 3(10):1470-1476. https://doi.org/10.1371/journal. ppat.0030151

15. Zheng X, Xu Y, Guan W, Lin L (2018) Regional, age and respiratory-secretion-specific prevalence of respiratory viruses associated with asthma exacerbation: a literature review. Arch Virol 163(4):845-853. https://doi.org/10.1007/s00705-017-3700-y

16. Wu P, Zeng S, Yin G et al (2020) Clinical manifestations and risk factors of adenovirus respiratory infection in hospitalized children in Guangzhou, China during the 2011-2014 period. Medicine (Baltim) 99(4):e18584. https://doi.org/10.1097/MD.0000000000 018584

17. Wang Y, Dong T, Qi G et al (2018) Prevalence of common respiratory viral infections and identification of adenovirus in hospitalized adults in Harbin, China 2014 to 2017. Front Microbiol 9:2919. https://doi.org/10.3389/fmicb.2018.02919

18. du Prel J-B, Puppe W, Gröndahl B, Knuf M, Weigl F, Schaaff F, Schaaff F, Schmitt H-J (2009) Are meteorological parameters associated with acute respiratory tract infections? Clin Infect Dis 49(6):861-868. https://doi.org/10.1086/605435

19. Bakir J, Juárez MDV, Lución MF et al (2020) Clinical and epidemiological study of acute lower respiratory tract infections caused by adenovirus in hospitalized children. Nineteen years of active epidemiological surveillance. Arch Argent Pediatr 118(3):193201. https://doi.org/10.5546/aap.2020.eng.193

20. Cattoir L, Vankeerberghen A, Boel A, Van Vaerenbergh K, De Beenhouwer H (2019) Epidemiology of RSV and hMPV in Belgium: a 10-year follow-up. Acta Clin Belg 74(4):229-235. https:// doi.org/10.1080/17843286.2018.1492509

21. Kenmoe S, Bigna JJ, Well EA et al (2018) Prevalence of human respiratory syncytial virus infection in people with acute respiratory tract infections in Africa: a systematic review and meta-analysis. Influenza Other Respir Viruses 12(6):793-803. https://doi. org/10.1111/irv.12584

22. Yassine HM, Sohail MU, Younes N, Nasrallah GK (2020) Systematic review of the respiratory syncytial virus (RSV) prevalence, genotype distribution, and seasonality in children from the Middle East and North Africa (MENA) region. Microorganisms 8(5):713. https://doi.org/10.3390/microorganisms 8050713
23. Yassine HM, Sohail MU, Younes N, Nasrallah GK (2020) Efficacy of face mask in preventing respiratory virus transmission: a systematic review and meta-analysis. Travel Med Infect Dis 36:101751. https://doi.org/10.1016/j.tmaid.2020.101751

24. Leung NHL, Chu DKW, Shiu EYC et al (2020) Respiratory virus shedding in exhaled breath and efficacy of face masks. Nat Med 26(5):676-680. https://doi.org/10.1038/s41591-020-0843-2

25. Radonovich LJ Jr, Simberkoff MS, Bessesen MT et al (2019) N95 respirators vs medical masks for preventing influenza among health care personnel. JAMA 322(9):824-833. https://doi.org/10. 1001/jama.2019.11645

26. Chu DK, Akl EA, Duda S et al (2020) Physical distancing, face masks, and eye protection to prevent person-to-person transmission of SARS-CoV-2 and COVID-19: a systematic review and meta-analysis. Lancet 395(10242):1973-1987. https://doi.org/10. 1016/S0140-6736(20)31142-9

27. Phillips B, Browne DT, Anand M, Bauch CT (2021) Model-based projections for COVID-19 outbreak size and student-days lost to closure in Ontario childcare centres and primary schools. Sci Rep 11:6402. https://doi.org/10.1038/s41598-021-85302-6

28. Hu F, Jing L, Shi R (2020) Analysis of related factors and disease costs of respiratory infection and environmental pollution in children. Technol Health Care 28(Suppl 1):355-360. https://doi.org/ 10.3233/THC-209036

29. Xia X, Zhang A, Liang S, Qi Q, Jiang L, Ye Y (2017) The Association between air pollution and population health risk for respiratory infection: a case study of Shenzhen, China. Int J Environ Res Public Health 14(9):950. https://doi.org/10.3390/ijerph1409 0950

30. Lam TT, Tang JW, Lai FY et al (2019) Comparative global epidemiology of influenza, respiratory syncytial and parainfluenza viruses, 2010-2015. J Infect 79(4):373-382. https://doi.org/10. 1016/j.jinf.2019.07.008

Publisher's Note Springer Nature remains neutral with regard to jurisdictional claims in published maps and institutional affiliations. 